\title{
EDITORIAL
}

\section{Treatment of right heart failure on pulmonary arterial hypertension: is going left a step in the right direction?}

\author{
R. Naeije
}

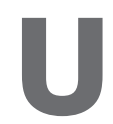
ntil in the early 1990s, pulmonary arterial hypertension (PAH) was consistently fatal, with a median life expectancy of $\sim 2.5$ yrs. Uncontrolled studies showed that a small proportion of patients responded to high-dose calcium channel blockers and retrospective studies supported the use of anticoagulants, with heart-lung or lung transplantation remaining the only option. Since then, there has been remarkable progress with the introduction of targeted therapies based on the administration of prostacyclins, endothelin receptor antagonists and phosphodiesterase- 5 inhibitors. However, the disease has remained incurable and median survival is still limited to $\sim 5-6$ yrs, with insufficient functional improvement in many of the survivors [1]. Thus, there is room for innovative thinking. This is precisely what HANDOKO et al. [2] have done in the current issue of the European Respiratory Review. Taking a refreshing physiological point of view, the authors acknowledge that advanced stage $\mathrm{P}(\mathrm{A}) \mathrm{H}$ symptomatology and prognosis is essentially determined by the state of the right ventricle, and that, contrary to prevailing belief, currently prescribed targeted therapies do not act on the right ventricle. As a result, HANDOKO et al. [2] have come forward with proposals derived from the treatment of left heart failure, including cautious but decisive use of $\beta$-blocker therapies and, in selected cases, resynchronisation therapy.

50 years ago, WooD [3] proposed the "vasoconstrictive factor" as the primum movens of severe pulmonary hypertension. The idea was inspired by observations of transient decrease in pulmonary vascular resistance following injection of acetylcholine [3] or tolazaline [4] directly into the pulmonary artery, and reversal of the disease after surgical correction of left-to-right cardiac shunts when lung biopsies showed only pulmonary arteriolar medial hypertrophy [5]. HEATH et al. [5] and WAGENVOORT [6] subsequently proposed morphological criteria of vasoconstriction as a cause of further remodelling of the entire pulmonary vascular wall and eventual plexiform, and coined the term "plexogenic pulmonary vasculopathy". Decades of research have failed to identify the vasoconstrictive factor proposed by WOOD [3], but paved the way for the understanding of multi-signalling endothelial control of pulmonary vascular tone and structure, which achieved proof

CORRESPONDENCE: R. Naeije, Depts of Pathophysiology and Cardiology, Erasme Hospital, Free University of Brussels; 808 Route de Lennik, 1070 Brussels, Belgium. E-mail: rnaeije@ulb.ac.be

Received: Dec 22 2009; Accepted: Dec 232009

PROVENANCE: Submitted article, peer reviewed. of concept from the success of targeted therapies [7]. There is no arguing that all these drugs are pulmonary vasodilators. However, because of clinical improvement with little change in pulmonary artery pressure, there has been suggestion of supplemental modes of action including anti-vasoproliferative effects and improved right ventricular function [8].

HANDOKO et al. [2] present an elegant haemodynamic analysis showing inverse directional changes of stroke volume and pulmonary artery pressure in randomised controlled trials of targeted therapies in PAH, leaving little space for direct inotropic effects. As for the reversal of vasoproliferation, this is of course difficult to demonstrate in patients. The concept of $\mathrm{PAH}$ as a vasoproliferative rather than a vasoconstrictive disease [9] has initiated basic research on a variety of molecular pathways shown to be activated in advanced forms of the disease [10]. However, this has not yet delivered bedside translation, except for a few isolated, and so far unreproduced, success stories [11]. WoOD [3] may still be right that effective pulmonary hypertension therapies have to be pulmonary vasodilating, as may HEATH et al. [5] and WAGENVOORT [6] that reversibility is a matter of early intervention.

So, what are the prospects for patients with advanced PAH? Lung function does not seem to be an issue. There is little or no perturbation in lung function tests in these patients. Furthermore, studies using the sophisticated multiple inert gas elimination technique have shown that their distributions of ventilation-perfusion $(\mathrm{V} / \mathrm{Q})$ relationships are close to normal, at rest [12,13] as well as during exercise [14]. The mean $\mathrm{V} / \mathrm{Q}$ is shifted to higher $\mathrm{V} / \mathrm{Q}$, which decreases the efficiency of gas exchange and increased physiological dead space, but the resulting arterial partial pressure of oxygen $\left(\mathrm{PO}_{2}\right)$ often remains normal or low to normal [12-14]. Hypoxaemia is explained by a low mixed venous $\mathrm{PO}_{2}$, a result of a low cardiac output [12-14]. In some patients, hypoxaemia is caused by right to left shunting through a patent foramen ovale [13]. In spite of vascular obliteration, dead space remains normal or near-normal, and increased physiological dead space only partly accounts for a resting and exercise hyperventilation that does not limit exercise capacity [14-16].

Symptoms of PAH are typically triggered by physical activity. Could it be the skeletal muscles? The maximal capacity of an individual to perform aerobic work is defined by the maximal oxygen uptake $\left(V^{\prime} \mathrm{O}_{2}, \max \right)$. Oxygen uptake is equal to the product of maximum cardiac output by the arteriovenous oxygen-content difference. Because of the sigmoid shape of the oxyhaemoglobin dissociation curve, with high affinities for 
oxygen at high and low saturations, there is an inferior limit of mixed venous $\mathrm{O}_{2}$ content attained at the highest level of exercise. However, $V^{\prime} \mathrm{O}_{2}$, max is achieved on a bicycle with approximately half of the body's muscles, and there is no data to suggest skeletal muscle (or $\mathrm{O}_{2}$ extraction) limitation to exercise capacity in (right) heart failure. It is, therefore, a reasonable assumption that aerobic exercise capacity in $\mathrm{PAH}$, as in heart failure, is essentially cardiac output limited [17]. There has been suggestion of decreased maximal systemic $\mathrm{O}_{2}$ extraction at exercise in $\mathrm{PAH}$ patients compared to patients with left heart failure [18]. However, this result could be explained [19] by slight nonlinearity of the relationship between cardiac output and $\mathrm{O}_{2}$ extraction, and higher cardiac outputs achieved by PAH patients in that study [18].

Thus, it has to be the heart. However, the measurements of pulmonary vascular pressures and flows during a standard right heart catheterisation do not provide an adequate evaluation of ventricular pump function [20]. HANDOKO et al. [2] correctly reason that the adaptation of right ventricular function to after load is, in essence, systolic, or homeometric, with secondary heterometric changes occurring in cases of excess of peripheral demand for increased flow. A right heart that is adequately adapted to increased pulmonary artery pressures remains normal in size, with an increased contractility matching pulmonary arterial elastance, at least at rest [21]. Systolic function is defined by end-systolic elastance, which can be measured, together with arterial elastance, at the bedside from single beat analysis of right ventricular pressure curves and pulmonary blood flow integration [22]. НANDOKO et al. [2] believe in the graphical analysis of right ventricular pump function, which plots mean right ventricular pressure as a function of stroke volume, as was initially proposed by ELZINGA and Westerhof [23]. Indeed this looks easier, but it still requires the calculation of a maximal right ventricular pressure at a stroke volume equal to zero, relies on a curve synthesised from only two data points and is preload-dependent. However, thinking in terms of pump function has allowed HANDOKO et al. [2] to unravel the mode of action, cardiac versus pulmonary vascular, of pulmonary circulation-targeted therapies. Indeed, available measurements are not suggestive of either positive or negative inotropic effects.

If one accepts the notion of $\mathrm{PAH}$ as a (right) heart failure syndrome, it makes a lot of sense to take a look at the left. The treatment of left heart failure includes a series of interventions of established efficacy aimed at the control of excessive neurohumoral activation, asynchrony of ventricular contraction and arrythmia. So, how about the right? Severe pulmonary hypertension has been shown to delay right ventricular contraction, with associated impairment of systolic function and negative diastolic interaction with the left ventricle [24]. Right ventricular asynchronic contraction may be identified by tissue Doppler imaging as a post-systolic shortening [25]. HANDOKO et al. [26] have already provided evidence that resynchronisation of the right ventricle improves exercise capacity and survival in rats with monocrotaline-induced pulmonary hypertension. This path is now open for clinical investigation.

As for neurohumoral activation in right heart failure, nobody would get upset about the suggestion by HANDOKO et al. [2] of adding angiotensin converting enzyme inhibitors or angiotensin II antagonists to the therapeutic armamentarium of PAH. These drugs are usually well tolerated in heart failure, and there is experimental evidence of efficacy of angiotensin II antagonists in experimental over circulation-induced $\mathrm{PAH}$ [27]. More controversial are $\beta$-blockers. The negative inotropic effects of these drugs carry the risk of right ventriculo-arterial uncoupling, as shown acutely in experimental animals [22] There is clinical experience of exacerbation of dyspnoea and fatigue in patients with $\mathrm{PAH}$ accidentally exposed to $\beta$ blockers. Withdrawal of these drugs in patients with portopulmonary hypertension has been shown to improve exercise capacity and functional state [28]. $\beta$-blockers are administered in these patients for the prevention of bleeding from oesophageal varices. However, in light of the overwhelming evidence of sympathetic nervous system over-activation in PAH, HANDOKO et al. [2] intend to try it anyway; cautiously and at low doses, which are, after all, how $\beta$-blockers are prescribed to patients with left heart failure. They will probably consider first providing more experimental animal evidence that it works, and are very clear that $\beta$-blockers, like any new treatment for $\mathrm{PAH}$, are to be tried only in strictly controlled randomised trials. Further considerations by HANDOKO et al. [2] about the prevention of arrythmia and sudden death may seem less convincing, as both are felt to be relatively uncommon in $\mathrm{PAH}$. Again, more research is needed here.

The PAH community has devoted considerable efforts in recent years through consensus conferences and guidelines. This has produced very useful, detailed codification of everything currently available to improve the lives of the patients afflicted with this dire disease. However, more progress is needed, and this can only be achieved by input of renewed perspectives, like those proposed by HANDOKO et al. [2]. As the French proverb states, "Du choc des idées jaillit la lumière".

\section{STATEMENT OF INTEREST}

R. Naeije has received reimbursements of travel expenses to congresses and speakers' fees from Actelion, Pfizer, GlaxoSmithKline, Bayer, Lung $\mathrm{Rx}$, United Therapeutics and Mondobiotech. He has also participated on advisory boards for Actelion, Mondobiotech, United Therapeutics and Lung Rx, and has received funds for research from Actelion and Pfizer.

\section{REFERENCES}

1 McLaughlin VV, Archer SL, Badesch DB, et al. ACCF/AHA 2009 Expert Consensus Document on Pulmonary Hypertension. A Report of the American College of Cardiology Foundation Task Force on Expert Consensus Documents and the American Heart Association. Circulation 2009; 119: 2250-2294.

2 Handoko ML, de Man FS, Allaart CP, et al. Perspectives on novel therapeutic strategies for right heart failure in pulmonary arterial hypertension: lessons from the left heart. Eur Respir Rev 2010; 19: 72-82.

3 Wood P. Pulmonary hypertension with special reference to the vasoconstrictive factor. Br Heart J 1958; 20: 557-570.

4 Dresdale DT, Mitchom RJ, Schultz M. Recent studies in primary pulmonary hypertension, including pharmacodynamic observations on pulmonary vascular resistance. Bull NY Acad Med 1954; 30: 195-207.

5 Heath D, Helmholz HF, Burchell HB, et al. Relationship between structural changes in the pulmonary arteries and the immediate reversibility of pulmonary hypertension following closure of ventricular and atrial septal defects. Circulation 1958; 18: 1167-1174. 
6 Wagenvoort CA. Plexogenic arteriopathy. Thorax 1994; 49: S39-S45.

7 Humbert M, Sitbon O, Simonneau G. Treatment of pulmonary arterial hypertension. $N$ Engl J Med 2004; 351: 1425-1436.

8 Rich S. The current treatment of pulmonary arterial hypertension. Time to redefine success. Chest 2006; 130: 1198-1202.

9 Rubin LJ. Therapy of pulmonary hypertension: the evolution of vasodilators to antiproliferative agents. Am J Respir Crit Care Med 2002; 166: 1308-1309.

10 Michelakis ED, Wilkins MR, Rabinovitch M. Emerging concepts and translational priorities in pulmonary arterial hypertension. Circulation 2008; 118: 1485-1495.

11 Ghofrani HA, Seeger W, Grimminger F. Imatinib for the treatment of pulmonary arterial hypertension. N Engl J Med 2005; 353: 14121413.

12 Dantzker DR, Bower JS. Mechanisms of gas exchange abnormality in patients with chronic obliterative pulmonary vascular disease. J Clin Invest 1979; 64: 1050-1055.

13 Melot C, Naeije R, Mols $\mathrm{P}$, et al. Effects of nifedipine on ventilation/perfusion matching in primary pulmonary hypertension. Chest 1983; 83: 203-207.

14 Dantzker DR, D’Alonzo GE, Bower JS, et al. Pulmonary gas exchange during exercise in patients with chronic obliterative pulmonary hypertension. Am Rev Respir Dis 1984; 130: 412-416.

15 Deboeck G, Niset G, Lamotte M, et al. Cardiopulmonary exercise testing in pulmonary arterial hypertension and in congestive heart failure. Eur Respir J 2004; 23: 747-751.

16 Sun XG, Hansen JE, Oudiz RJ, et al. Exercise pathophysiology in patients with primary pulmonary hypertension. Circulation 2001; 104: 429-435.

17 Fleg JL, Pina IL, Balady GJ. Assessment of functional capacity in clinical and research applications: an advisory from the committee on exercise, rehabilitation, and prevention, council on clinical cardiology, American Heart Association. Circulation 2000; 102: 1591-1597.

18 Tolle J, Waxman A, Systrom D. Impaired systemic oxygen extraction at maximum exercise in pulmonary hypertension. Med Sci Sport Exerc 2008; 40: 3-8.
19 Wong YY, Van Laarse W, Vonk Noordegraaf A. Reduced systemic oxygen extraction does not prove muscle dysfunction in PAH. Med Sci Sports Exerc 2008; 40: 1554-1555.

20 Champion HC, Michelakis ED, Hassoun PM. Comprehensive invasive and noninvasive approach to the right ventricle-pulmonary circulation unit. State of the Art and clinical research applications. Circulation 2009; 120: 992-1007.

21 Kuehne T, Yilmaz S, Steendijk P, et al. Magnetic resonance imaging analysis of right ventricular pressure-volume loops: in vivo validation and clinical application in patients with pulmonary hypertension. Circulation 2004; 110: 2010-2016.

22 Brimioulle S, Wauthy P, Ewalenko P, et al. Single-beat estimation of right ventricular end-systolic pressure-volume relationship. Am J Physiol Heart Circ Physiol 2003; 284: H1625-H1630.

23 Elzinga G, Westerhof N. How to quantify pump function of the heart. The value of variables derived from measurements on isolated muscle. Circ Res 1979; 44: 303-308.

24 Marcus JT, Gan CT, Zwanenburg JJ, et al. Interventricular mechanical asynchrony in pulmonary arterial hypertension: leftto-right delay in peak shortening is related to right ventricular overload and left ventricular underfilling. J Am Coll Cardiol 2008; 51: 750-757.

25 Huez S, Faoro V, Vachiery JL, et al. Images in cardiovascular medicine. High-altitude-induced right-heart failure. Circulation 2007; 115: 308-309.

26 Handoko ML, Lamberts RR, Redout EM, et al. Right ventricular pacing improves right heart function in experimental pulmonary arterial hypertension: a study in the isolated heart. Am J Physiol Heart Circ Physiol 2009; 297: H1752-H1759.

27 Rondelet B, Kerbaul F, Van Beneden R, et al. Prevention of pulmonary vascular remodeling and of decreased BMPR-2 expression by losartan therapy in shunt-induced pulmonary hypertension. Am J Physiol Heart Circ Physiol 2005; 289: H2319H2324.

28 Provencher S, Herve P, Jais X, et al. Deleterious effects of betablockers on exercise capacity and hemodynamics in patients with portopulmonary hypertension. Gastrenterology 2006; 130: 120-126. 